\title{
LOS GESTOS DE LUTERO A LA LUZ DE LAS MODERNIZACIONES EN POLÍTICA Y ECONOMÍA
}

Hernán Gabriel Borisonik ${ }^{1}$

\section{Resumen:}

Teniendo en cuenta que la tradición del pensamiento político vinculó casi "naturalmente" el auge del capitalismo y el individualismo con la herencia luterana sin bucear profundamente bastante en los detalles y particularidades que caracterizan a esta unión, este artículo tiene como objetivo hacer un análisis más complejo de estos aspectos. Si bien es claro que uno de los sellos más fuertes de la primera modernidad ha sido el avance de las nuevas relaciones sociales y económicas y de la secularización progresiva de aspectos que antes sólo estaban conectados al dominio sagrado, también es cierto que aun el poder religioso estaba en una situación de privilegio en relación con la posibilidad de ser obedecido, de interpretar la revelación y de imponer sus disposiciones sobre la sociedad civil.

Palabras-clave: Lutero. Política. Economía. Modernidad. Sacralidad.

Una de las lecturas más aceptadas de la teoría política contemporánea (basada en ideas de Max Weber) sostiene que el individualismo moderno ha sido un aporte del protestantismo. Bajo esa premisa, se ha vinculado, sin más, al nacimiento del capitalismo con la Refirma protestante. Sin embargo, recién hace pocos años han aparecido aportes teóricos e historiográficos que ponen en duda (o, al menos, matizan) el énfasis de tal afirmación. Sea como sea, un dato es certero: en el camino de su reforma, Lutero condensó muchas de las tensiones que determinaron los rumbos del Occidente moderno, dado que fue quien pretendió separar categóricamente a lo material y lo político de lo espiritual, pero, simultáneamente, fue quien propuso que el gobierno civil castigue a los "pecadores". La propuesta de este artículo es, entonces, analizar algunos aspectos concretos de las normativas

\footnotetext{
${ }^{1}$ Doctor en Ciencias Sociales por la Universidad de Buenos Aires. Docente e investigador en temas de Teoría Política de la Universidad de Buenos Aires. Becario CONICET. E-mail: hborisonik@sociales.uba.ar
}

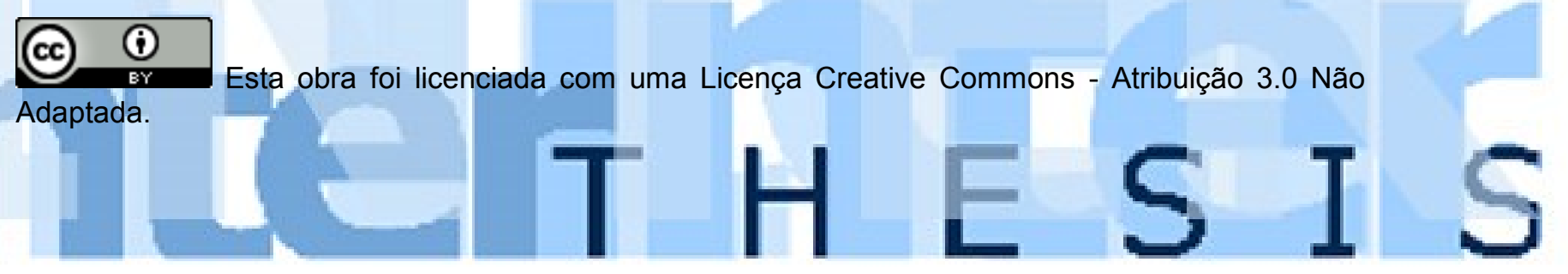


católicas y protestantes de cara a la irrupción de nuevas formas políticas y económicas que transformaron la vida de Occidente.

La llamada Temprana Modernidad representó, entre otras cosas, un importante proceso de secularización, es decir, un pasaje de lo religioso a lo jurídico que estuvo signado por la centralización del poder político y dio origen a los Estados nacionales. Dos de los rasgos más salientes de tal transformación han sido la positivización de las normas y la aparición de sujetos jurídicos individuales, portadores de derechos y obligaciones. Como podrá observarse, ambas características han sido robustecidas por el legado de la Reforma Protestante. De todas maneras, al ser una etapa de transición, muchas de las categorías que la Modernidad más acabada habría de comprender como dicotomías, se encontraban aun expresadas con mayor sutileza y sin límites tan claros. En ese contexto, la figura de Lutero ha cobrado una importancia cardinal, dado que sus acciones implicaron un fuerte quiebre a las doctrinas de la Iglesia católica y, además, porque marcó un fundamental reposicionamiento de los diversos grupos sociales que conformaban al escenario alemán. Es preciso aclarar que en tales circunstancias, "lo político" y "lo religioso" eran discursos mutuamente permeados y superpuestos, siendo muy difícil (más allá de la intención luterana) hallar un límite concreto y tajante entre ambas esferas analíticas.

Precisamente, debido a la falta de precedentes revolucionarios y a la ausencia de un Estado consolidado, la Reforma protestante y las guerras campesinas acabaron por reforzar la condensación y concentración del poder político en manos de las autoridades seculares, intensificando la tendencia hacia la distinción entre las morales privadas y las leyes públicas, colocando a las primeras en el ámbito de lo individual (donde fueron colocadas la fe y las acciones económicas) y a las últimas como imposición sobre la sociedad en su conjunto.

Una de las características más distintivas de la organización políticoeconómica de Edad Media era la superposición de diversas lógicas que concebían, con relativa independencia, a la autoridad, al terreno y al gobierno. Pero mientras que la geografía descentralizada y fuertemente fragmentada del sistema feudal tendía a la dispersión del poder, la Iglesia y el Imperio eran fuerzas de concentración y unidad, cuya autoridad era centralizada pero no implicaba sujeción territorial. Estas lógicas conformaban jurisdicciones superpuestas que aplicaban (de manera no exclusiva) formas de dominio y de adjudicación de derechos y deberes sobre los

R. Inter. Interdisc. INTERthesis, Florianópolis, v.11, n.1, p.84-103, Jan./Jun. 2014
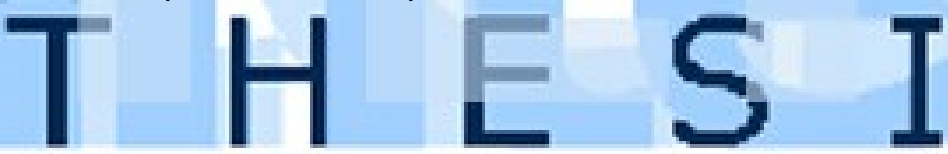
diversos estamentos sociales. Esta superposición fue la causa de no pocos conflictos, sobre todo hacia los siglos XV y XVI, en los que la pretendida universalidad de la Iglesia comenzó a chocar con mayor potencia con las fuerzas locales de los florecientes poderes que pretendían unificar regionalmente las soberanías de facto de los diferentes señores y príncipes. Por otra parte, existía un complejo entramado impositivo, en el que se entrecruzaban los tributos feudales con los impuestos imperiales y los eclesiásticos, de modo que la economía local y basada en la subsistencia se encontraba atravesada por redes comerciales y financieras que mantuvieron una red en todo el continente europeo. En pocas palabras, tanto en materia política como económica, la soberanía jurisdiccional no era leída en términos estrictamente territoriales o geográficos.

Por todo ello, sólo cuando el proceso modernizador estuvo más avanzado fue que aquellas cuestiones que en la Edad Media eran tomadas como contrastes (bajo una gran síntesis moral unificadora en manos de la Iglesia), pasaron a interpretarse como antítesis: así, para un moderno es natural pensar a la vida espiritual contra la vida práctica, a la religión contra los apetitos, al espíritu contra la materia, etc. Pero hasta entrado el siglo XVI, absolutamente todo tenía aun fuertes ribetes religiosos.

Frente a ello, un eje que guiará estas reflexiones estará colocado en mostrar la intensa y profunda relación que tenían, en su fase más temprana, aquello que la Modernidad denominaría como esferas religiosa, política y económica. Lo que desde el siglo XVIII se intentaría separar, no se hallaba originalmente delimitado. Lo que se encuentra es, más bien, una intersección jurisdiccional que a fin de cuentas nunca ha podido demarcarse de modo absoluto, pues lo que existe, finalmente, no es más que una compleja constelación que hace a la vida humana y su organización. Incluso hoy sería ilusorio pretender afirmar que "lo político", "lo religioso", "lo jurídico" o "lo económico" existen como ámbitos estancos y definidos. Por eso, revisitar una de las posturas que más ha influido en la conformación del paradigma moderno occidental es fundamental para profundizar en su comprensión o incluso en su posible reconducción.

Por todo lo anterior, es preciso dar cuenta del rol que tuvo la Iglesia, no sólo a nivel espiritual y doctrinal, sino también como actor político y económico. Ya desde el siglo XIII habían comenzado a levantarse sospechas sobre Roma por su fuerte papel en los asuntos mundanos. Como lo explica Richard Tawney (1959, p. 34): “[...]

R. Inter. Interdisc. INTERthesis, Florianópolis, v.11, n.1, p.84-103, Jan./Jun. 2014
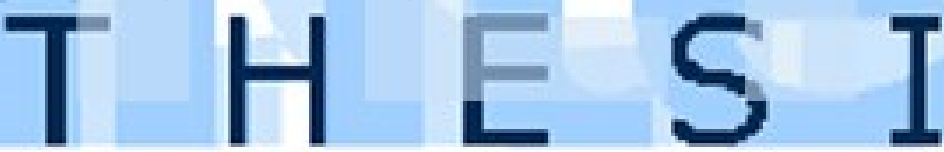
el papado era la más grande institución financiera de la Edad Media". Y luego agrega, haciendo alusión al Inocente IV:

Podía denunciar el Vaticano a los usureros; pero como centro del sistema administrativo más altamente organizado de la época, recibiendo remesas de toda Europa, y recibiéndolas en dinero en una época en que los ingresos de todos los demás gobiernos incluían todavía servicios personales y pagos en especie, no podía desprenderse de ellos [...]. Un Papa les otorgó el título de «hijos peculiares de la Iglesia romana» (TAWNEY, 1959, p. 34).

De todas maneras, la vinculación de la Iglesia con actividades comerciales y financieras no sucedió sólo en los niveles más altos (cardenales, obispos), sino también desde las escalas menores de la curia, y no solamente en Roma. En toda la orbe cristiana existieron párrocos que negociaban perdones por acciones usureras a cambio de donaciones para las iglesias y parroquias. Justamente, las fuertes denuncias que propugnó el Concilio de Trento en contra de estos vicios son una importante prueba de cuán extendidos se encontraban en la época y de la necesidad de combatirlos. De hecho, podría afirmarse que las especulaciones económicas escolásticas fueron un intento por "reconciliar las nuevas relaciones contractuales, que surgían de la expansión económica, con la moralidad tradicional expuesta por la Iglesia" (TAWNEY, 1959, p. 35).

En un contexto de fuertes cambios, el Vaticano se había transformado en un centro de inmenso poder político y económico, hecho que la convirtió en el blanco de duros ataques, por no ceñirse a su función original de guía espiritual de la comunidad cristiana. Frente a tales condiciones, Lutero surgió en el escenario teológico con la determinación de reformar a la cristiandad. Así, desarrolló su doctrina de los dos reinos (Zwei-Reiche-Lehre) que apoyaba la división entre lo espiritual y lo material, poniendo en posesión de los príncipes todo el poder político y dejando las cuestiones de fe en manos de Dios. Con ello, buscó deshacerse de las jerarquías religiosas y limitar los vínculos entre los hombres de fe y las acciones económicas.

Al respecto, uno de los problemas fundamentales que Lutero mantuvo con Roma se hallaba íntimamente vinculado con el dinero. Al observar la obra que inauguró la Reforma Protestante esto queda evidenciado: Lutero censuró el planteo de que el Papa poseía la capacidad de perdonar los pecados de las almas que se

R. Inter. Interdisc. INTERthesis, Florianópolis, v.11, n.1, p.84-103, Jan./Jun. 2014
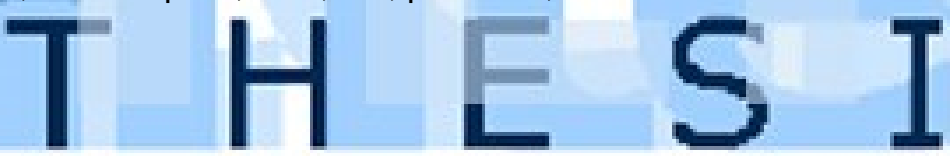
encontrasen en el Purgatorio ${ }^{2}$. Pues, además de poner en duda la existencia de tal ámbito, al estar las almas desafectadas de la materialidad no podían, según el fraile alemán, ser objeto de perdón humano sino solamente divino. Para Lutero, el único con el poder de juzgar las conciencias es Dios, lo cual lo indujo a desestimar las penas -y las recompensas- eclesiásticas y, simultáneamente, a sacralizar el derecho positivo de los príncipes sobre los cuerpos.

Pese a no figurar en la Biblia, la postura del Concilio de Trento, frente a los ataques protestantes, fue la defensa de la existencia del Purgatorio:

\begin{abstract}
Habiendo la Iglesia católica, instruida por el Espíritu Santo, según la doctrina de la sagrada Escritura y de la antigua tradición de los Padres, enseñado en los sagrados concilios, y últimamente en este general de Trento, que hay Purgatorio; y que las almas detenidas en él reciben alivio con los sufragios de los fieles, y en especial con el aceptable sacrificio de la misa; manda el santo Concilio a los Obispos que cuiden con suma diligencia que la sana doctrina del Purgatorio, recibida de los santos Padres y sagrados concilios, se enseñe y predique en todas partes, y se crea y conserve por los fieles cristianos [...]. Mas cuiden los Obispos que los sufragios de los fieles, es a saber, los sacrificios de las misas, las oraciones, las limosnas y otras obras de piedad, que se acostumbran hacer por otros fieles difuntos, se ejecuten piadosa y devotamente según lo establecido por la Iglesia (CONCILIO DE TRENTO, sesión XXV, 3 y 4 de diciembre de 1563).
\end{abstract}

Por otra parte, Lutero veía con infinita indignación al hecho de que se cobrase dinero por tal indulgencia. Por un lado, porque acercaba a los usureros (a los que consideraba entre las peores clases de hombres) a la ilusión de una vida eterna en Dios, dándoles, de hecho, ventajas por sobre los pobres; y por otro lado, porque hacía de la Iglesia una feria de indulgencias. La venta de perdones ocupó, en efecto, un lugar importante entre las 95 tesis de 1517. En la tesis 27, Lutero declaraba: "Mera doctrina humana predican aquellos que aseveran que tan pronto suena la moneda que se echa en la caja, el alma sale volando". Y en la siguiente es aún más rotundo: "Cierto es que, cuando al tintinear, la moneda cae en la caja, el lucro y la avaricia pueden ir en aumento, más la intercesión de la Iglesia depende sólo de la voluntad de Dios". Dado que el perdón es sólo producto de la gracia divina, las leyes mundanas (incluso las sacramentales, si no figuran en la Biblia) no tienen mayor

\footnotetext{
${ }^{2}$ Sobre la cuestión del purgatorio, ver Greenblatt (2001); acerca del vínculo entre la usura y el purgatorio, ver Le Goff (1979).
}

R. Inter. Interdisc. INTERthesis, Florianópolis, v.11, n.1, p.84-103, Jan./Jun. 2014 
utilidad que satisfacer, con soberbia humana, la avidez de conseguir la salvación por medio de obras. Ante ello, el Concilio de Trento respondería:

Habiendo Jesucristo concedido a su Iglesia la potestad de conceder indulgencias, y usando la Iglesia de esta facultad que Dios le ha concedido, aun desde los tiempos más remotos; enseña y manda el sacrosanto Concilio que el uso de las indulgencias, sumamente provechoso al pueblo cristiano, y aprobado por la autoridad de los sagrados concilios, debe conservarse en la Iglesia, y fulmina antema contra los que, o afirman ser inútiles, o niegan que la Iglesia tenga potestad de concederlas" (CONCILIO DE TRENTO, sesión XXV, 4 de diciembre de 1563).

Lo que Lutero pretendía evitar era que la Iglesia continuara siendo un ente de recaudación fiscal. Según su doctrina, el buen cristiano debía vivir haciendo caridad, pero no pagando impuestos, sino dándole a su prójimo, a su vecino, a los miembros de su comunidad. Le parecía problemático que la Iglesia cobrase cánones como si fuera una institución terrenal, lo cual ayudó a la consolidación de los poderes seculares.

Pero simultáneamente al desarrollo de los Estados, la modernización llegó de la mano de un florecimiento comercial y mercantil de inmensa magnitud, que implico, asimismo, un cambio en la mentalidad de los gobernantes. Las palabras luteranas eran superadas mientras se escribían. Pues mientras que favorecían la concentración del poder político, eran ya poco adecuadas frente al avance de las intenciones monopólicas de las grandes familias financieras que supieron asociarse con los príncipes desde el origen mismo de las naciones europeas.

El ideal del Renacimiento ascendió junto con la racionalidad matemática que todo lo mide y que impuso, al mismo tiempo, la idea de que todo tiene también un precio. Por eso, el nacimiento del Purgatorio y la posibilidad de comprar un lugar en el cielo no implicaron un escándalo para los pobres cristianos, sino solamente para algunos pastores educados que veían un mecanismo perverso en la venta de indulgencias (que permitía a los usureros tener la ilusión de una vida eterna en el Paraíso).

Si bien toda la tradición antigua se había mostrado hostil a que el dinero engendrara dinero, desde el siglo XV circulaban ya opiniones que trataban con menor dureza tales actividades, probablemente como consecuencia del incremento del ritmo y volumen de los intercambios comerciales y del florecimiento de las casas

R. Inter. Interdisc. INTERthesis, Florianópolis, v.11, n.1, p.84-103, Jan./Jun. 2014
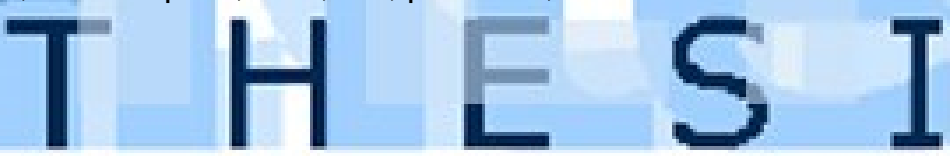
bancarias. Lo mismo ocurrió en el seno de la Iglesia, pues mientras que durante varios siglos todos los concilios habían castigado fuertemente a la usura, desde 1515 se empezaron a modificar las leyes del derecho canónico sobre la economía, debido a los fuertes cambios en el escenario comercial europeo y la aparición de América en el mapa comercial.

En ese sentido Lutero recuperó ideales pasados, sosteniendo que el mal uso del dinero se alejaba de las verdaderas necesidades humanas. En 1519, afirmaba en su Sermón contra la usura (Große Sermon von dem Wucher) que, luego del Diablo, el usurero era el peor enemigo de los hombres, pues es quien desea que los demás estén en la ruina, que haya hambre y miseria, para que todos dependan de él y poder así incrementar su fortuna. Con sus acciones, estos hombres desoían, incluso, al precepto luterano de los dos reinos y los dos gobiernos, pues, por ejemplo, el emperador germano Carlos $\mathrm{V}$ debió modificar en varias ocasiones sus posturas a instancias de las presiones de la casa Fugger, acreedora de un importante número de nobles, incluyendo al propio Carlos (cuya elección como emperador fue también financiada con dinero de esta casa). ${ }^{3}$ Al respecto, importa recordar la centralidad que dicha familia (la principal entre otras que se dedicaban a las mismas actividades) mantuvo a la hora de marcar los rumbos políticos durante gran parte del siglo XVI.

Las empresas comerciales y financieras tuvieron un rol cardinal, dado que pusieron a disposición de los príncipes una serie de créditos y herramientas económicas (como las letras de cambio), sin las cuales su poder hubiese mermado sensiblemente. Eran organizaciones que, además, tenían fuertes conexiones con la venta de manufacturas e incluso también con la minería y otras actividades tendientes a la mercantilización, no sólo en Alemania, sino también en la Península Ibérica y en el Nuevo Mundo conquistado. La presión producida por los intentos monopólicos de estas casas fue uno de los factores que influyó en la enemistad entre Carlos V y Lutero, quien se alineó con los movimientos antimonopólicos que surgieron a partir de 1512. Estos movimientos se oponían a las grandes empresas que fijaban precios y adquirian productos con fines especulativos. A causa de sus pedidos, diversas Dietas alemanas confeccionaron leyes que, sistemáticamente,

\footnotetext{
${ }^{3}$ Sobre tal cuestión, ver Ehrenberg (2012).
}

R. Inter. Interdisc. INTERthesis, Florianópolis, v.11, n.1, p.84-103, Jan./Jun. 2014
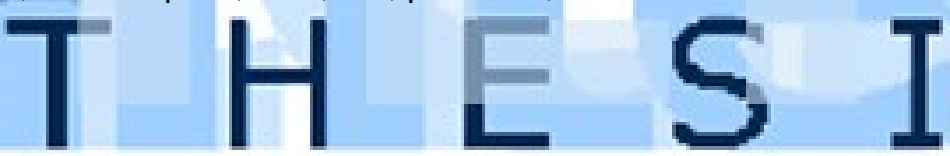
fueron sorteadas por la incipiente burguesía con ayuda de las excepciones dictadas por el emperador. Esto muestra con claridad la mutua dependencia entre los grandes poderes políticos y económicos ya en las fases más primitivas del capitalismo. El problema al que se enfrentaban estos grupos era la fuerte brecha que se estaba abriendo entre las legislaciones civiles y las religiosas.

Según Lutero, la pretensión de los usureros era gobernar el mundo terrenal con el dinero, hallando en la especulación económica un fuerte enemigo de la comunidad humana ${ }^{4}$, que se oponía a la voluntad divina de que un gobierno secular se ocupara de todas las cuestiones materiales y físicas. Igualmente, cabe aclarar que, por su situación histórica, Lutero no fue capaz de ver el cuadro completo de las transformaciones político-económicas que se dieron entre los siglos XV y XVI, por lo que el único enemigo que encontró a su alcance fue el préstamo con intereses, sin ser capaz de advertir ciertas técnicas menos centradas en las personas individuales que acompañaron y dieron forma al incipiente capitalismo. De todas formas, es interesante notar cómo ya en este entorno hace su aparición el problema del gobierno legítimo (elegido, en este caso, por Dios) contra el gobierno de facto de los ricos, vinculado al poder económico y a la ambición ilimitada de acumular riquezas.

Lutero se expresó con mucha violencia en contra de los intereses financieros, al punto de inspirar a los campesinos a sublevarse contra los príncipes. Precisamente, allí se encuentra una de las fuentes del, por momentos, paradojal legado de la Reforma Protestante. Lutero hablaba en contra de la usura, pero nunca centró sus críticas en las enormes desigualdades políticas que, sin duda alguna, estaban fuertemente vinculadas a aquella.

El problema es que en la realidad de la Alemania del siglo XVI ambos factores eran prácticamente inseparables. Si, por un lado, los banqueros y la cúpula romana eran denunciados como anti-cristianos, los pobres ya no eran los destinatarios del discurso religioso, sino potenciales peligros para la sociedad, pues magro podía ser

\footnotetext{
${ }^{4}$ Estos hechos ponen en duda algunas de las hipótesis de Max Weber (2003) acerca de la profunda articulación entre protestantismo y capitalismo, dado que, si por un lado la primera expresión reformista (es decir, Lutero) se muestra opuesta a la usura, por otro lado la iglesia católica durante el siglo XVI fue muy ambigua respecto de tales actividades. Sobre esta cuestión, es esclarecedor el trabajo de Jean Delumeau (1965, p. 301-326). Además, un análisis histórico (y no sociológico) demuestra que los roles de la Iglesia católica y de la Reforma Protestante han sido diferentes a los descriptos por Weber (TREVOR ROPER, 2001). No obstante, es preciso destacar que Weber fue un precursor en advertir que economía y religión se encontraban íntimamente ligadas, pese a haberlo percibido como un vínculo externo, cuando en realidad es intrínseco.
}

R. Inter. Interdisc. INTERthesis, Florianópolis, v.11, n.1, p.84-103, Jan./Jun. 2014
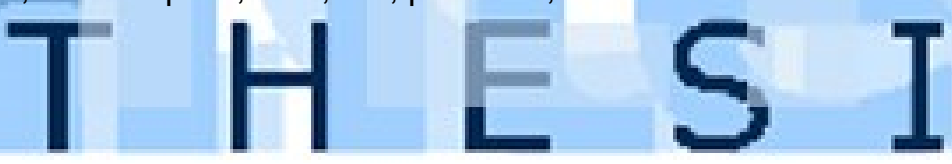
su aporte para el bien del prójimo. Así, Lutero y otros reformistas se comprometieron en cruzadas para combatir la pobreza, apoyando, de un lado, créditos sin intereses y alentando la vida consagrada a la artesanía o las actividades agrícolas; pero, al mismo tiempo, Lutero se mostró muy crítico con aquellos que aceptaban su condición de pobreza sin volcarse al trabajo, lo cual lo llevó a emitir potentes declaraciones sobre la necesidad de matar a los campesinos sublevados o de ahorcar a los mendigos y a los "reacios al trabajo" (como declara en su Von Konzilien und Kirchen). De ese modo, así como este fraile agustino criticó al Papa por inmiscuirse en lo que no le correspondía, Münzer lo llamó "el Papa de Wittemberg", en alusión a una acción similar. De todos modos, Lutero nunca tomó las armas en sus propias manos y su lucha fue siempre a nivel doctrinal.

Respecto de las revueltas, para Lutero una cosa era una reforma religiosa y pacífica en la cristiandad y otra muy distinta era modificar las jerarquías políticas derramando sangre. El cambio perseguido por Lutero tenía que ver con un regreso a determinados valores del cristianismo primitivo. Pero no a todos: precisamente el autogobierno que marcó a los primeros cristianos fue reemplazado en la Reforma Protestante, por una absoluta verticalidad política. Lutero intentó distinguir entre los poderes material y espiritual, y entre las leyes seculares (producidas por la razón humana) y sagradas (la Biblia). La razón humana, que no significaba nada ante Dios, debía regir sobre la tierra de la mano de los nobles.

Para Lutero, sin un claro orden político (encabezado por la nobleza, a cualquier precio), el Evangelio no podría ser enseñado ni predicado. Para él, Dios no otorgaba el poder de coerción a todos, sino sólo a los más altos espíritus que saben cómo utilizarlo, pues si todos lo tuvieran el mundo sería una permanente guerra y el diablo triunfaría. Pues, para Lutero, allí donde el poder secular no hace un firme y estricto uso de la fuerza -y dado que la mayoría de la humanidad no pertenece verdaderamente al cristianismo-, todo el mundo toma todo lo que puede, mata y viola, por lo que no hay ninguna seguridad.

Como se observa, la Reforma Protestante y las revueltas campesinas del siglo XVI se encontraban inmersas en un contexto en el cual delito y pecado no habían cobrado aun identidades separadas y aislables (aunque mutuamente implicadas durante, al menos, un siglo más). Pero la obra luterana fue un paso fundamental hacia la positivación del derecho. Al intentar separar absolutamente la esfera espiritual de la material, Lutero otorgó a los príncipes temporales una

R. Inter. Interdisc. INTERthesis, Florianópolis, v.11, n.1, p.84-103, Jan./Jun. 2014

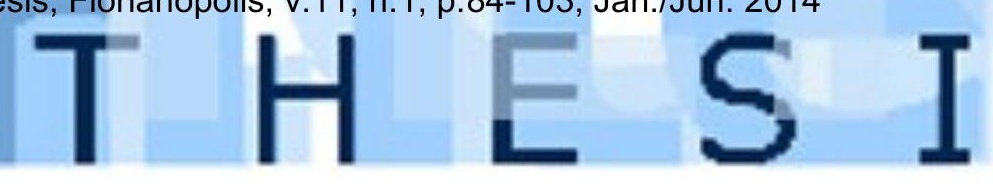


omnipotencia total sobre los cuerpos y las acciones externas, dando pié a la aparición de un fuero interno regulado espiritualmente por Dios. De ese modo, así como las lenguas, las iglesias comenzaron a vernaculizarse, dejando de tener un poder efectivo a la hora de aplicar penas. Con ello, los Estados ganaron una batalla fundamental en relación con el monopolio del uso de la fuerza legítima. Paolo Prodi lo enuncia de este modo: "en conjunto, las reformas fueron respuestas a las crisis propias del paso de un sistema de reglamentos jurídicos rivales a un sistema de dualismo entre el reglamento positivo emergente y la conciencia cristiana" (PRODI, 2008, p. 204).

Para comprender con mayor profundidad la acción de la Iglesia frente a los cambios políticos y económicos, tanto como sus reacciones de cara a la Reforma protestante, será importante revisar algunos de los artículos más importantes sostenidos por el Concilio de Trento como modo de oposición doctrinal al protestantismo.

La llamada primera muralla contra los romanistas que había declarado Lutero en su escrito "A la nobleza cristiana de la Nación alemana, acerca del mejoramiento del Estado cristiano" ("An den christlichen Adel deutscher Nation von des christlichen Standes Besserung"), se encuentra una fuerte crítica a la separación entre poder clerical y poder secular que sostenía la doctrina católica. Allí, Lutero afirma que absolutamente todos los hombres deben someterse al poder político imperante, más allá de su condición eclesiástica o laica. Según su doctrina, los príncipes deben gobernar sobre todo lo mundano y sólo Dios rige sobre las almas, de modo que los miembros de la Iglesia no deben arrogarse poder alguno sobre los cuerpos.

Sin embargo, el Concilio declaró que son los "Príncipes a quienes Dios ha encomendado casi todo el gobierno de las cosas" (Papa Paulo III. Bula convocatoria del Concilio de Trento), dejando un margen para su propio poder. Asimismo, en los Cánones sobre el sacramento del orden, el Concilio declararía:

Si alguno dijere, que no hay en el nuevo Testamento sacerdocio visible y externo; o que no hay potestad alguna de consagrar, y ofrecer el verdadero cuerpo y sangre del Señor, ni de perdonar o retener los pecados; sino sólo el oficio, y mero ministerio de predicar el Evangelio; o que los que no predican no son absolutamente sacerdotes; sea excomulgado. [...] Si alguno dijera, que no hay en la Iglesia católica jerarquía establecida por institución divina, la cual consta de Obispos, presbíteros y ministros; sea excomulgado (CONCILIO DE TRENTO, sesión XXIII, 15 de julio de 1563).

R. Inter. Interdisc. INTERthesis, Florianópolis, v.11, n.1, p.84-103, Jan./Jun. 2014
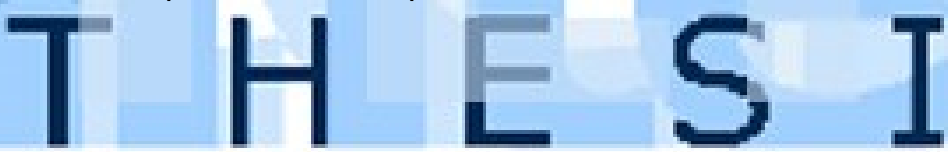
Por su parte, el Concilio reafirma también las diferentes jerarquías adentro de la Iglesia y no sólo su distinción y legitimidad frente al poder secular. De este modo, contra las ideas luteranas, la Iglesia continuó proclamando tener un derecho diferente del de los laicos, pudiendo, además, decidir imponer multas pecuniarias y excomulgando a quien se considere necesario. En pocas palabras, se sostuvo la distinción entre lo canónico y lo secular.

Por ello, para la Iglesia era importante conservar el monopolio de la transmisión del conocimiento religioso a los fieles. Por eso ordenó que sólo prediquen quienes estuvieran autorizados y solamente en los sitios en los que estuvieran autorizados, impidiendo cualquier intromisión que no estuviese examinada y aprobada por la Iglesia:

Eviten los Obispos permitir que predique bajo pretexto de privilegio ninguno en su ciudad o diócesis, persona alguna, ya sea de los que siendo Regulares en el nombre, viven fuera de la clausura y obediencia de sus religiones, o ya de los Presbíteros seculares, a no tenerlos conocidos y aprobados en sus costumbres y doctrina; hasta que los mismos Obispos consulten sobre el caso a la santa Sede Apostólica; de la que no es verisímil saquen personas indignas semejantes privilegios, a no ser callando la verdad, y diciendo mentira. Los que recogen las limosnas, que comúnmente se llaman Demandantes, de cualquiera condición que sean, no presuman de modo alguno predicar por sí, ni por otro; y los contraventores sean reprimidos (CONCILIO DE TRENTO, sesión V, 17 de junio de 1546).

La segunda muralla que intentó derribar Lutero era el monopolio de la lectura e interpretación de las sagradas Escrituras que la Iglesia se atribuía. La posición protestante fue la apertura de la Biblia a toda la cristiandad. Cuestión que, apoyada por la aparición de la imprenta en Alemania, fue muy bien recibida por muchos. Contra esta postura, el Concilio expresaría que es función de la Iglesia decidir

[...] qué edición de la sagrada Escritura se ha de tener por auténtica [...]; establece y declara, que se tenga por tal en las lecciones públicas, disputas, sermones y exposiciones, esta misma antigua edición Vulgata, aprobada en la Iglesia por el largo uso de tantos siglos; y que ninguno, por ningún pretexto, se atreva o presuma desecharla. Decreta además, con el fin de contener los ingenios insolentes, que ninguno fiado en su propia sabiduría, se atreva a interpretar la misma sagrada Escritura en cosas pertenecientes a la fe, y a las costumbres que miran a la propagación de la doctrina cristiana, violentando la sagrada Escritura para apoyar sus dictámenes, contra el sentido que le ha dado y da la santa madre Iglesia, a la que

R. Inter. Interdisc. INTERthesis, Florianópolis, v.11, n.1, p.84-103, Jan./Jun. 2014

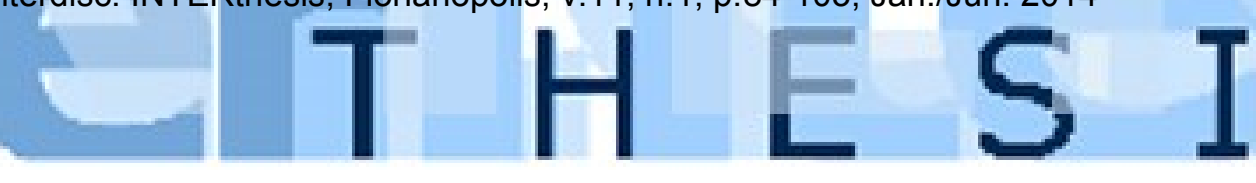


privativamente toca determinar el verdadero sentido, e interpretación de las sagradas letras (CONCILIO DE TRENTO, sesión IV, 8 de abril de 1546).

Asimismo, el Concilio instó a los impresores a editar solamente dicha versión de la Biblia y les prohibió publicar notas o comentarios de autores no aprobados, bajo la pena de excomunión y/o de ser multados económicamente. Sumado a eso, la voluntad de la Iglesia era que las misas se celebraran exclusivamente en latín y que las lenguas vulgares se utilizaran para que los párrocos y curas explicaran sencillamente a los fieles las lecciones de la Biblia.

En relación con las finanzas, el Concilio de Trento instó a los fieles cristianos a continuar pagando sus diezmos tradicionales, cuestión que se había visto perjudicada por la aparición de fuertes poderes políticos y de las iglesias protestantes. El pedido de la Iglesia fue el siguiente:

\begin{abstract}
No se deben tolerar las personas que valiéndose de varios artificios, pretenden quitar los diezmos que caen a favor de las iglesias; ni los que temerariamente se apoderan y aprovechan de los que otros deban pagar: pues la paga de los diezmos es debida a Dios, y usurpan los bienes ajenos cuantos no quieren pagarlos, o impiden que otros los paguen. Manda, pues, el santo Concilio a todas las personas de cualquier grado y condición a quienes toca pagar diezmos, que en lo sucesivo paguen enteramente los que de derecho deban a la catedral, o a cualesquiera otras iglesias o personas, a quienes legítimamente pertenecen. Las personas que o los quitan, o los impiden, excomúlguese, y no alcancen la absolución de este delito, a no seguirse la restitución completa. Exhorta además a todos, y a cada uno de los fieles, por la caridad cristiana, y por la debida obligación que tienen a sus pastores, tengan a bien socorrer con liberalidad de los bienes que Dios les ha concedido, a gloria del mismo Dios, y por mantener la dignidad de los pastores que velan en su beneficio, a los Obispos y párrocos que gobiernan iglesias muy pobres (CONCILIO DE TRENTO, sesión XXV, 3 y 4 de diciembre de 1563).
\end{abstract}

Otro punto fundamental en la disputa entre católicos y protestantes fue la cuestión de la predeterminación contra el libre albedrío. La doctrina luterana sostuvo la idea de la predestinación, es decir de la imposibilidad de obtener la salvación por obras externas o voluntarias, puesto que para Dios los salvos (los verdaderos cristianos, marcados por la fe) ya estaban señalados y nada podría cambiar eso.

Frente a tales concepciones, el Concilio (basado en gran parte en los escritos de Erasmo, tras su disputa con Lutero), sostendría la existencia del libre arbitrio humano, como lo muestran varias de sus fórmulas. Entonces, las obras sí tienen

R. Inter. Interdisc. INTERthesis, Florianópolis, v.11, n.1, p.84-103, Jan./Jun. 2014

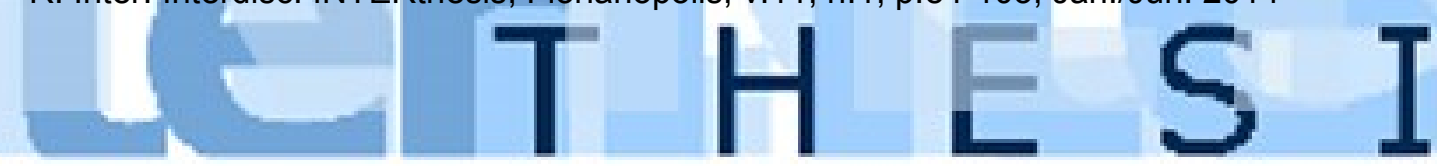


peso a la hora de saber si alguien sería salvo o no, puesto que, al creer en el libre arbitrio humano, el juicio divino sería posterior a la obra. Otra gran diferencia es que para la Iglesia, sólo era posible llegar al Cielo gracias a la mediación eclesiástica y no (como en el planteo luterano) en un vínculo directo con Dios:

Jesucristo, Señor nuestro, único mediador, que nos reconcilió con Dios por medio de su pasión, hecho para nosotros justicia, santificación y redención; [...] el mismo mérito de Jesucristo se aplica así a los adultos, como a los párvulos por medio del sacramento del bautismo, exactamente conferido según la forma de la Iglesia (CONCILIO DE TRENTO, sesión V, 17 de junio de 1546);

Si alguno dijere, que todos los cristianos tienen potestad de predicar, y de administrar todos los Sacramentos; sea excomulgado. [...] Si alguno dijere, que no se requiere en los ministros cuando celebran, y confieren los Sacramentos, intención de hacer por lo menos lo mismo que hace la Iglesia; sea excomulgado. [...] Si alguno dijere, que se pueden despreciar u omitir por capricho y sin pecado por los ministros, los ritos recibidos y aprobados por la Iglesia católica, que se acostumbran practicar en la administración solemne de los Sacramentos; o que cualquier Pastor de las iglesias puede mudarlos en otros nuevos; sea excomulgado (CONCILIO DE TRENTO, sesión VII, 3 de marzo de 1547).

Así, dado que no somos todos sacerdotes, sólo pueden predicar los ordenados por la Iglesia:

[...] prohíbe a todos los fieles cristianos, que en adelante se atrevan a creer, enseñar o predicar respecto de la santísima Eucaristía de otro modo que el que se explica y define en el presente decreto (CONCILIO DE TRENTO, sesión XIII, 11 de octubre de 1551);

[...] cualquiera que afirmase que todos los cristianos son promiscuamente sacerdotes del nuevo Testamento, o que todos gozan entre sí de igual potestad espiritual; no haría más que confundir la jerarquía eclesiástica, que es en sí como un ejército ordenado en la campaña; y sería lo mismo que si contra la doctrina del bienaventurado san Pablo, todos fuesen Apóstoles, todos Profetas, todos Evangelistas, todos Pastores y todos Doctores [...] todos los que destinados e instituidos sólo por el pueblo, o potestad secular, o magistrado, ascienden a ejercer estos ministerios, y los que se los arrogan por su propia temeridad, no se deben estimar por ministros de la Iglesia, sino por rateros y ladrones que no han entrado por la puerta (CONCILIO DE TRENTO, sesión XXIII, 15 de julio de 1563).

Por ello, para la Iglesia era tan importante el bautismo en manos de un clérigo ordenado según el canon. Pues, lejos del sacerdocio universal luterano, sólo aquellos que llegaran a Dios a través de la Iglesia serían salvados. $Y$ dado que hay libre albedrío, la salvación se consigue con fe y obras. De modo que la postura

R. Inter. Interdisc. INTERthesis, Florianópolis, v.11, n.1, p.84-103, Jan./Jun. 2014 
oficial de la Iglesia es que el hombre se justifica por sus obras, y no sólo por la fe. En conclusión, según el Concilio, sin fe no hay gracia, pero sin obra tampoco es posible salvarse. La obra es importante, porque existe el libre albedrío humano.

Precisamente, el interés supremo de Lutero, por encima de cualquier otro, era la cuestión de la salvación de las almas. Pero a contrapelo de la posición escolástica, sostuvo que no existe vínculo alguno entre las obras externas y la salvación, pues ésta sólo es alcanzable a través de la misericordia divina. Entonces, bajo esta perspectiva, el alma no pertenece al mundo ni puede estar regida por las normas humanas o el derecho secular, sino que tiene una relación directa e individual con Dios.

Lutero se dedicó a criticar todos los aspectos que consideró falsos acerca de la interpretación imperante sobre los mandatos divinos, comenzando por la idea de que era posible salvar las almas mediante acciones externas. El valor humano se encontraba, para él, totalmente disociado del éxito, la gloria o la fama, de modo que comenzó una batalla que acabó por tener varios frentes: uno contra la ostentación y la politicidad del Vaticano y otro contra la usura del nuevo sistema financiero que se encontraba apenas emergiendo. Sus palabras calaron tan hondo en la mentalidad de sus seguidores, que las banderas de la Reforma fueron levantadas con fines sociales y políticos mucho más profundos que los que Lutero podría haber imaginado. Sin embargo, lejos de apoyarlos, los enfrentó con gran vehemencia, convirtiéndose éstos en un tercer blanco para sus acusaciones.

Un rasgo sobresaliente del Medioevo había sido la idealización discursiva de la pobreza. Esto tranquilizaba a las masas y daba a los ricos la idea de que la limosna era un medio para llegar al Paraíso en la otra vida. No obstante, si bien Lutero no proclamó ningún tipo de apego por lo material (al contrario, más bien lo vilipendiaba), sostuvo que ninguna obra -incluso la más virtuosa para la opinión de los demás- implicaba la salvación de las almas, de modo que si alguien se encontraba librado de todo lo material no estaría en mejor posición que cualquier otro cristiano a la hora del Juicio Final. A ojos de Lutero, el dinero no era un elemento malo en sí mismo. Según él, Dios lo puso sobre la tierra para servir a los demás y afianzar los lazos comunales y para que los hombres hagan un buen uso de él, pero no para la usura, que sí era vista como una acción malvada. De modo que tan perverso y equivocado estaba quien abusaba de los préstamos y buscaba la riqueza ilimitada, como quien renunciaba a los bienes procurando llegar al cielo.

R. Inter. Interdisc. INTERthesis, Florianópolis, v.11, n.1, p.84-103, Jan./Jun. 2014
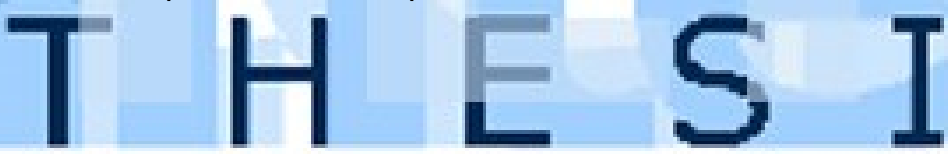
Ambas eran comprendidas por Lutero como formas incorrectas de usar al dinero, pues en los dos casos se dejaban de lado las necesidades ajenas. Justamente, la gran pobreza (junto con el consecuente incremento de la vagancia) que caracterizó al final de la Edad Media había sido, en algún sentido, legitimada por la doctrina de la Iglesia y exacerbada por las acciones económicas de los más ricos.

El rechazo de Lutero por las obras como forma de salvación fue absoluto. Atacó sistemáticamente a los sacramentos, las limosnas, las órdenes mendicantes, etc. La vida cotidiana debía, para él, ocupar todo el espacio de lo terrenal y nada "extraordinario" debería hacerse, pues no aportaba en nada a la vida eterna. Por eso, también luchó por la supresión del derecho canónico, pues consideraba que la Biblia alcanzaba como instructivo para la vida cualquier buen cristiano (sin intercesión de la Iglesia). Previendo, en algún sentido, la universalidad moral kantiana, Lutero sostuvo que con mandatos bíblicos tales como "ama a tu prójimo como a ti mismo" o "lo que quisieras que los demás hagan contigo, hazlo con los demás" debería alcanzar para una vida buena y ordenada, sin necesidad de leyes ni gobiernos. El rechazo de la razón es, entonces, absoluto. No sólo es mera soberbia humana, sino que es contraproducente a nivel social. Para Lutero, toda positivación o exteriorización de las reglas divinas las degradaba. Y eso terminó por ponerlo en una posición poco asible que se prestó a diversas interpretaciones.

La Reforma comenzada por Lutero ha sido uno de los núcleos fundamentales de la Modernidad. Más allá de la claridad o las intenciones que pueda haber tenido su iniciador, su querella con Roma ha sentado las bases para nuevas concepciones acerca de los vínculos sociales, de la afirmación territorial de los Estados y de la libertad en términos de consciencia y de fe. El individualismo fue una consecuencia (tal vez no buscada, aunque claramente ocurrida) de la Reforma. Pero el primer imperialismo comercial y financiero del capitalismo surgió en las coronas católicas de España y Portugal. El capitalismo moderno tuvo origen al mismo tiempo que las primeras grandes fortunas que fueron amasadas en relación con la especulación financiera (vinculada, a su vez, con los monopolios) y la usura (también con ciertos nexos con los seguros marítimos).

Las primeras grandes compañías financieras nacieron en Italia, ya antes del siglo XV. El ejemplo más importante en Alemania fueron los Fugger, relacionados, en principio, con la minería, pero luego convertidos en uno de los poderes más influyentes de toda Europa. Tanto ellos, como los Medici y los Thurzo eran familias

R. Inter. Interdisc. INTERthesis, Florianópolis, v.11, n.1, p.84-103, Jan./Jun. 2014
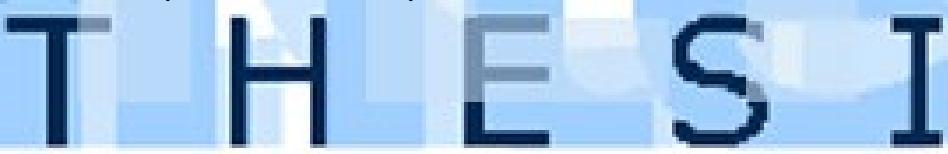
cristianas y obtuvieron el apoyo de las altas esferas de la Iglesia. Estas compañías aprovecharon la consolidación del comercio fijo y urbano (ya no en forma de ferias) y la aparición de bolsas de comercio, en las que se negociaban valores que representaban a las mercancías. Ya desde sus orígenes, los actores más influyentes del capitalismo no estaban asentados en la industria, sino en la especulación.

Como lo explica Humberto Mandelli (1980, p. 79),

los primeros capitalistas son oriundos de la Iglesia o han sido guiados por ella, como el caso de los banqueros de la Curia, o a veces los mismos Papas, que se dejaban ganar por la fiebre capitalista, como el caso de León $X$ [...] [que] en razón de su origen y sobre todo de la potencia y firmeza de su fe, no podían concebir que en su comportamiento pudiera haber algo reprochable.

Por su parte, Lutero tomó una posición fuerte en contra de estas nuevas empresas monopolistas. En una de sus declaraciones sostuvo que había que poner una brida en la boca de la santa compañía de los Fugger. ${ }^{5}$ Por ello, Tawney (1959, p. 96) afirmó que

Su actitud [la actitud luterana] hacia la conquista de la sociedad por el mercader y el financista es idéntica a su actitud hacia la comercialización religiosa. Cuando contempla la Iglesia en Alemania, la ve empobrecida por los tributos impuestos por la nueva Babilonia. Cuando contempla la vida social germana, la ve dominada por un poder económico sin conciencia.

La Reforma llegó para juzgar, a partir de un pasado cristiano idealizado, las acciones de un presente cambiante y corrupto. Pero en un momento de tantos movimientos y modificaciones, sostener este conservadurismo extremo implicó convertirse en un revolucionario. En Lutero se combinan un odio a las laxitudes morales, un individualismo espiritual y un anti-individualismo económico, para dar lugar a un pedido de orden y control a las autoridades seculares.

Por ello, no es posible explicar todo el complejo entramado que surgió en el siglo XVI solamente vinculando la Reforma con el individualismo económico. Si la Temprana Modernidad representó la aparición de nuevas formas, fue también porque los siglos anteriores habían gestado crisis y dislocaciones sociales.

\footnotetext{
5 "Hie müsste man wahrlich auch den Fuckern und der geistlichen Gessellschaft einen Zaum ins Maul legen" (EHRENBERG, 2012, p. 312), tomado del texto luterano, de 1540, A los párrocos, para predicar contra la usura.
}

R. Inter. Interdisc. INTERthesis, Florianópolis, v.11, n.1, p.84-103, Jan./Jun. 2014
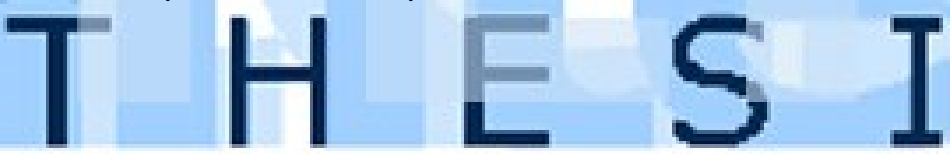
Para Lutero debía renacer la idea de comunidad cristiana: por un lado comunidad religiosa como congregación de creyentes, y, por el otro, comunidad social desde la caridad. En ambas, cada uno debería ocupar una función, que no hace a una esencia, sino a la necesidad. En ese caso, no harían falta las jerarquías. Pero como existen tan pocos cristianos en el mundo, y debido que la humanidad es pura naturaleza caída, Dios pone sobre la tierra a hombres que están llamados a gobernar y ordenar a las sociedades, defendiendo a los buenos y castigando a los malos. El gobierno secular, en este contexto, es necesario y deseado por Dios. En él se concentran las jerarquías que falsamente la Iglesia ha colocado en la espiritualidad y los usureros en las diferencias económicas construidas a base de injusticias. El mundo debe ser gobernado por Dios (indirectamente en lo material, a través de los príncipes y directamente en lo espiritual, de manera individual y por el Espíritu Santo).

El "individualismo" luterano no es, entonces, una expresión temprana del empresario sin conciencia social, sino un llamado al encuentro con lo divino y un pedido de menor atención hacia lo material. La comunidad luterana se compone de individuos que se manejan cumpliendo las funciones que Dios les impuso, dentro de las cuales ser caritativo es la primera. En eso no se diferencia de las demás religiones: Lutero sueña con un mundo gobernado a partir de los textos revelados (tanto en el aspecto moral y económico, como en el social y educativo) y concibe a la política como pura represión de las malas acciones (idealmente desde una perspectiva bíblica). No obstante, cabe hacer una salvedad: la caridad y el amor al prójimo son entendidos por Lutero como consecuencias de que todos los hombres son criaturas de Dios (es decir, no hay un amor hacia los otros porque son conciudadanos, hermanos o iguales en derechos, sino únicamente por el hecho de ser todos creados por Dios). Ese es el sentido profundo del célebre "individualismo luterano" y no el egoísmo económico que caracterizará a una Modernidad más avanzada. Pero al mismo tiempo, la igualdad absoluta de los hombres en el terreno espiritual y la secularización total de la vida terrenal fueron aspectos tan revolucionarios que, en efecto, serían las bases de todas las revueltas y manifestaciones durante los dos (o tres) siglos subsiguientes.

El rechazo de la obra como forma de salvación vino de la mano de la legitimación a gobiernos totalitarios. Lutero llegó a manifestar que es imposible regir

R. Inter. Interdisc. INTERthesis, Florianópolis, v.11, n.1, p.84-103, Jan./Jun. 2014
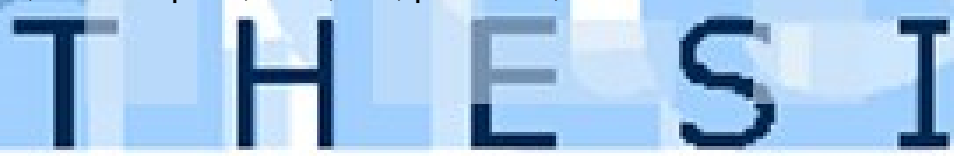
el mundo sin sangre y que la espada civil debe ser la encargada de hacerla brotar ${ }^{6}$. Todo esto fortaleció enormemente al nuevo "Deus mortalis" temeroso sólo de Dios que habrían de adorar Enrique VIII, Hobbes y Maquiavelo.

${ }^{6}$ Lutero. "Von Kaufshandlung und Wucher".

R. Inter. Interdisc. INTERthesis, Florianópolis, v.11, n.1, p.84-103, Jan./Jun. 2014

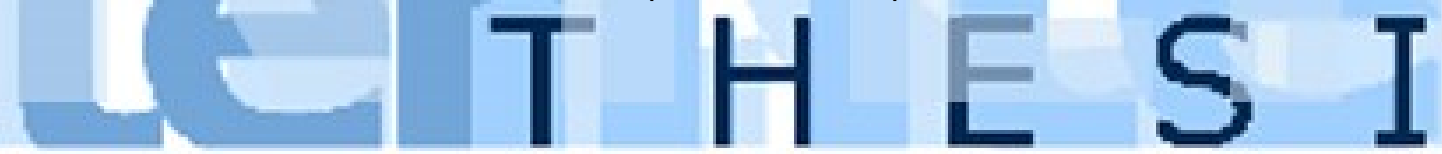




\title{
OS GESTOS DE LUTERO À LUZ DAS MODERNIZAÇÕES EM POLÍTICA E ECONOMIA
}

\section{Resumo}

Tendo em conta que a tradição do pensamento político tem vinculado quase "naturalmente" o surgimento do capitalismo e o individualismo com a herança luterana sem mergulhar com profundidade suficiente nos detalhes e particularidades que caracterizam esse vínculo, o presente artigo pretende fazer uma análise mais complexa desses aspectos. Embora seja claro que uma das mais fortes marcas da primeira Modernidade tem sido o avanço de novas relações sociais e econômicas e da secularização gradual de aspectos que até então só estavam ligados ao domínio sagrado, também é verdade que o poder religioso ainda mantinha uma situação de privilégio em relação à possibilidade de ser obedecido, de interpretar a revelação e de impor suas disposições sobre a sociedade civil.

Palavras-chave: Lutero. Política. Economia. Modernidade. Sacralidade.

\section{LUTHER'S HERITAGE IN THE LIGHT OF THE MODERNIZATIONS IN POLITICS AND ECONOMICS}

\begin{abstract}
The tradition of political thinking has "naturally" linked Lutheran legacy to the individualism and to the emergence of capitalism, without enough profundity in the particularities that have characterized such a bound. It is evident that one of the strongest marks of Early Modern Times has been the advancement of industry and the gradual legalization of aspects that until then were only linked to the sacred. It is also true that, even then, religious power was in a situation of privilege regarding the possibility of being obeyed, of interpreting the Revelation and of applying discretionally its will.
\end{abstract}

Keywords: Luther. Politics. Economy. Modern Times. Sacred.

R. Inter. Interdisc. INTERthesis, Florianópolis, v.11, n.1, p.84-103, Jan./Jun. 2014
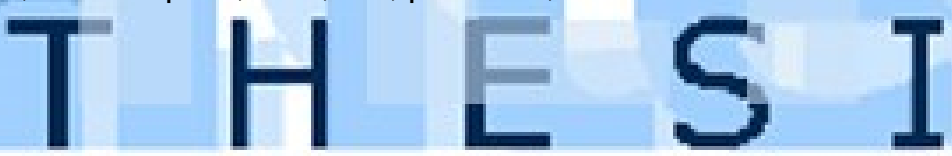


\section{REFERENCIAS}

CONCILIO DE TRENTO. Acceso em: 15 ago. 2013 Disponível em:

$<$ http://www.emym.org/articulos1/conciliodetrento.pdf>.

DELUMEAU, Jean. Naissance et affirmation de la Réforme. Paris: PUF, 1965.

EHRENBERG, Richard. Das Zeitalter Der Fugger: Geldkapital Und Kreditverkehr Im 16. Jahrhundert. Berlin: Let me Print, 2012.

GREENBLATT, Stephen. Hamlet in Purgatory. Princeton: Princeton University Press, 2001.

LE GOFF, Jacques. The Usurer and Purgatory. In: Chiappelli, Fredi (Ed.). The Dawn of Modern Banking. New Haven: Yale University Press, 1979. p. 25-52.

MANDELLI, Humberto A. Historia económica y social. Buenos Aires: Nueva Técnica, 1980.

PRODI, Paolo. Una historia de la justicia. Buenos Aires: Katz, 2008.

TAWNEY, Richard. La religión en el origen del capitalismo. Trad. Jaime Menéndez. Buenos Aires: Dédalo, 1959.

TREVOR ROPER, Hugh. The Crisis of the Seventeenth Century: Religion, the Reformation and Social Change. Indianapolis: Liberty Fund, 2001.

WEBER, Max. La ética protestante y el espíritu del capitalismo. Buenos Aires: Fondo de Cultura Económica, 2003.

\section{Artigo:}

Recebido em Agosto de 2013.

Aceito em Novembro de 2013

R. Inter. Interdisc. INTERthesis, Florianópolis, v.11, n.1, p.84-103, Jan./Jun. 2014
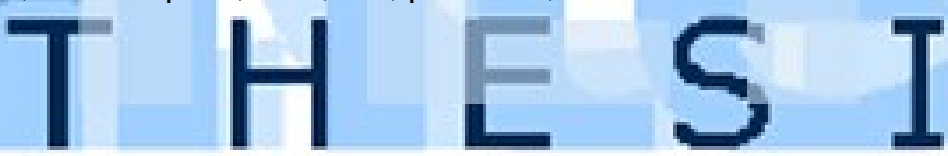